\title{
Stem Cell Therapies and Treatment Advances for Heart Failure with Preserved Ejection Fraction
}

\author{
Monica Soni, MSc ${ }^{1}$ (D) ${ }^{a}$, Brandon Ferrell ${ }^{1}$ b, Colin Wikholm ${ }^{1}$ c, L Tamara Wilson $^{1}{ }^{d}$ \\ ${ }^{1}$ School of Medicine, Georgetown University \\ Keywords: diastolic dysfunction, heart failure, biomarkers, stem cells \\ https://doi.org/10.52504/001c.12344
}

\section{Georgetown Medical Review}

Vol. 4, Issue 1, 2020

\begin{abstract}
Heart failure with preserved ejection fraction (HFpEF) is characterized by a left ventricular ejection fraction of $50 \%$ or greater. While heart failure with reduced ejection fraction ( $\mathrm{HFrEF}$ ) is well-characterized and has numerous treatment options, HFpEF remains poorly understood. HFpEF has long been termed diastolic dysfunction, because it was thought that fibrosis and impaired relaxation of the left ventricle could alone explain the underlying pathophysiology. However, recent research has identified additional mechanisms that influence HFpEF, specifically metabolic disorders and proinflammatory conditions. Despite this recent progress in elucidating the pathophysiology, there are still no approved treatment options that increase survival in patients with HFpEF. In the context of limited pharmacological options, stem cell therapy and cardiac biomarkers have emerged as potential breakthroughs in the treatment of HFpEF, but there has not yet been a review of their potential. This review evaluates the potential of cardiosphere-derived cells (CDCs), mesenchymal stromal cells (MSCs), and endothelial progenitor cells (EPCs) in the treatment of HFpEF. CDCs have shown promise, with a placebo-controlled animal trial demonstrating an increase in survival and a marked improvement in left ventricular end diastolic filling among the group treated with intracoronary infusion of CDCs.

Additionally, with the newfound understanding of HFpEF pathophysiology, studies have also investigated the role MSCs and EPCs play in the inflammation associated with HFpEF, as well as the potential benefit these stem cells would bring to the treatment of HFpEF. While clinical trials are needed to confirm the safety and efficacy of these therapies, we offer insight into their potential, as well as a comprehensive summary of the pertinent clinical studies that are currently in progress. Embase, Ovid Medline, and PubMed were used to search all relevant literature for this review.
\end{abstract}

\section{Introduction}

Heart failure, a significant cause of morbidity and mortality worldwide, can be classified into 2 distinct phenotypes based on left ventricular ejection fraction (LVEF): heart failure with reduced ejection fraction (HFrEF) and heart failure with preserved ejection fraction (HFpEF). ${ }^{1}$ According to the 2013 American College of Cardiology Foundation/American Heart Association Guidelines for the Management of Heart Failure, HFrEF is defined by a LVEF less than $40 \%$ and HFpEF by a LVEF of $50 \%$ or greater. ${ }^{2}$ Any LVEF of $40 \%$ or more

\footnotetext{
a Authors contributed equally to this work

b Authors contributed equally to this work.

c Authors contributed equally to this work.

d Authors contributed equally to this work.
} 
but less than $50 \%$ is classified as heart failure with minimally reduced ejection fraction; this condition responds well to HFrEF treatment and, thus, is considered a less severe form of HFrEF. ${ }^{2}$ While progress has been made in reducing the morbidity and mortality of HFrEF, a condition characterized by ventricular dilation and poor contractility of myocardium, the same is not true of HFpEF. 1,3 There are currently very limited treatment options for patients with HFpEF, who face similar rates of morbidity and mortality compared with patients with $\mathrm{HFrEF}{ }^{4}$ As a result, HFpEF, a condition characterized by preserved contractility of myocardium, represents a significant unmet medical need and a growing public health crisis.

The prevalence of HFpEF has been increasing over the past several decades and is rising at a rate of $1 \%$ per year relative to the prevalence of HFrEF. ${ }^{5}$ According to epidemiologic studies, individuals with HFpEF are more likely to be older and present with comorbidities compared with those with HFrEF. ${ }^{4}$ In addition, HFpEF accounts for approximately half of the global heart failure burden-a statistic that is only expected to increase given the sustained and unprecedented growth of the world's aging population. ${ }^{1}$ This growing public health crisis is compounded by a complete lack of gold-standard care for patients with HFpEF, which is due to the fact that the pathophysiologic mechanisms underlying the condition are complex, heterogeneous, and not well understood. ${ }^{4}$ Additionally, the diagnostic criteria for HFpEF is similarly complex and often based on the exclusion of other causes of heart failure. Consequently, research studies often do not exactly adhere to the current diagnostic guidelines when enrolling participants, thereby limiting the applicability of research findings specifically to HFpEF. ${ }^{4}$

Despite these limitations, recent research has improved understanding of HFpEF and its pathophysiology. HFpEF was previously referred to as diastolic dysfunction, because it was believed that myocardial stiffness and impaired relaxation of the left ventricle could alone explain the underlying pathophysiology - as the thinking went, stiffness led to reduced filling of the left ventricle, while preserved contractility of myocardium prevented a reduction in the ejection fraction. ${ }^{1}$ Research conducted over the past 20 years, however, suggests that these intrinsic cardiac mechanisms are not specific to patients with $\mathrm{HFpEF}$ and that additional mechanisms influence HFpEF pathophysiology, specifically metabolic disorders, proinflammatory conditions, and immunologic remodeling. 1,4 This understanding partly helps to explain why standard treatments for HFrEF, such as beta-blockers, diuretics, and angiotensin-converting enzyme inhibitors/angiotensin II receptor blockers have not been shown to decrease morbidity or mortality in patients with HFpEF. ${ }^{1}$ Statins, however, have been shown in several recent prospective cohort studies to decrease all-cause mortality among patients with HFpEF. ${ }^{6-8}$ The mechanism is not entirely understood, but it is thought that these benefits 
are due in part to the anti-inflammatory effects of statins. ${ }^{6}$ Nevertheless, these findings must be confirmed by adequately powered randomized clinical trials before statins can be officially approved for the treatment of HFpEF. 6,7

Current research is actively investigating potential therapies for HFpEF, with numerous pharmacological and nonpharmacological strategies under study. ${ }^{1}$ The lack of effective pharmacological treatment options to date has sparked interest in the study of nonpharmacological treatments for HFpEF, particularly stem cell therapy. While stem cell therapy is more invasive than other treatment options, it does have the potential to repair damaged tissue and reverse the progression of disease, which would be of value in the treatment of certain conditions such as HFpEF. ${ }^{9}$ To our knowledge, there has not been a single in-depth review article published on the potential for stem cell therapy in the treatment of HFpEF. Therefore, this review aims to provide insight into the ongoing research in this space-first by discussing why the newly accepted paradigm of HFpEF pathophysiology suggests a potential role for stem cell therapy, and then by reviewing the various types of stem cells currently under investigation for the treatment of HFpEF.

\section{Pathophysiology of HFpEF}

Cardiac output is a product of ventricular filling (diastole) and the force of ventricular contraction (systole). ${ }^{3} \mathrm{~A}$ common finding in patients with HFpEF is concentric hypertrophy of the left ventricle; this increase in the ratio of mass to volume is what allows for normal systolic function (preserved contractility of myocardium). ${ }^{3}$ Concentric hypertrophy is typically attributed to increased mechanical load, for example, due to persistent hypertension, but now there is research to suggest that neurohumoral activation and cytokines associated with other comorbidities may also contribute to the pathology. ${ }^{3}$

Fibrosis is another prominent characteristic of HFpEF and contributes to myocardial stiffening and diastolic dysfunction. ${ }^{4}$ However, while myocardial stiffening is primarily caused by excess collagen, there is evidence to suggest that fibrosis alone does not fully account for the diastolic dysfunction that characterizes HFpEF. ${ }^{4}$ This understanding comes from studies that identified patients with HFpEF who had normal collagen volume fractions, despite having myocardial stiffness comparable with those with elevated collagen volume fractions. ${ }^{4}$ Additionally, 1 study found patients with HFpEF and diabetes to have greater passive cardiomyocyte stiffness than patients with $\mathrm{HFpEF}$ and without diabetes, further suggesting that comorbidities influence this disease process. ${ }^{4}$ Clearly, the pathophysiology is multifaceted and more complex than simply diastolic dysfunction.

\section{Understanding the Role of Inflammation}

While left ventricular hypertrophy and myocardial stiffness are well-established characteristics of HFpEF, recent research suggests that inflammation is also a critical aspect of HFpEF pathophysiology. In a 2011 study, patients with 
HFpEF and controls underwent endomyocardial biopsies. In contrast to controls, patients with HFpEF had increased levels of collagen I and III proteins, as well as decreased expression of cardiac matrix metalloproteinase (MMP-1), thereby limiting the degree of collagen degradation. ${ }^{4}$ In addition, expression of tissue inhibitor of metalloproteinase was increased, further inhibiting collagen degradation. ${ }^{4}$ While abundant collagen deposition is expected in HFpEF, this study also found evidence of a relationship between cardiac inflammation and fibrosis in the pathogenesis of HFpEF. More specifically, the biopsies from patients with HFpEF demonstrated increased expression of vascular cell adhesion molecule-1, which functions to promote the migration of inflammatory cells-including those that secrete transforming growth factor- $\beta\left(\right.$ TGF- $\beta$ ) - to the myocardium. ${ }^{4}$ When harvested cardiac fibroblasts were cultured from the biopsy samples and incubated with transforming growth factor- $\beta$, they demonstrated increased collagen production and decreased MMP-1 expression; this suggests that cardiac inflammation has a direct impact on fibrosis and HFpEF pathophysiology. ${ }^{4}$

\section{A New Paradigm}

Given the preliminary evidence implicating inflammation in the pathogenesis of HFpEF, new paradigms recognizing the importance of hemodynamic stress, extracardiac mechanisms, and comorbidities have been proposed. ${ }^{4}$ Currently, the most well-accepted paradigm recognizes the high prevalence of cardiovascular and noncardiovascular comorbidities in patients with HFpEF, such as hypertension, valvular disease, obesity, diabetes, and chronic obstructive pulmonary disease. ${ }^{1,4}$ It is hypothesized that these comorbidities induce an inflammatory state, which is thought to contribute to the development of HFpEF through 2 pathways.

First, systemic inflammation is thought to result in coronary microvascular endothelial inflammation, reactive oxygen species production, and vascular rarefaction. ${ }^{1,4}$ This is the result of reactive oxygen species production reducing nitric oxide availability and protein kinase $\mathrm{G}$ activity in cardiomyocytes, as well as inducing endothelial cells to upregulate expression of vascular cell adhesion molecule-1, thereby stimulating the secretion of transforming growth factor$\beta$ by inflammatory cell infiltrates. ${ }^{1,4}$ Ultimately, the reduced activity of protein kinase $G$ promotes hypertrophy and increased tension due to hypophosphorylation of titin, a filamentous protein integral to cardiomyocyte contractility. 1,4

In addition, systemic inflammation is thought to have a direct impact on epicardial adipocytes. Under normal conditions, epicardial adipocytes secrete adiponectin, a hormone that works to shield cardiomyocytes from hypertrophic stimuli as well as reduce the formation of fibrosis in the myocardium; epicardial adipocytes also provide nutrients to surrounding tissues. ${ }^{10}$ However, systemic inflammation alters the function of epicardial adipocytes by promoting a proinflammatory phenotype. ${ }^{10}$ As a result, 
epicardial adipocytes decrease the production of adiponectin and begin secreting proinflammatory adipokines, such as tumor necrosis factor- $\alpha$, that promote fibrosis. ${ }^{10}$ These effects significantly impact the ventricular myocardium, with 1 study reporting a 50\% increase in ventricular epicardial adipose tissue among patients with HFpEF compared with controls. ${ }^{10}$ Collectively, these 2 pathways create an environment that supports hypertrophy, fibrosis, myocardial stiffness, and diastolic dysfunction.

\section{Stem Cell Therapies}

Stem cells have been the focus of extensive scientific research over the past several decades. In addition to being undifferentiated cells capable of selfrenewal, stem cells are able to differentiate into highly specialized, tissuespecific cells under certain conditions. ${ }^{11,12}$ As a result of these unique characteristics, stem cells are believed to hold promise for the treatment of countless diseases. With improved understanding of HFpEF pathophysiology, as well as the dearth of pharmacological therapy to treat HFpEF, there has been growing interest in stem cells as a potential therapy option.

\section{Stem Cell Classification}

Stem cells are broadly classified as either embryonic stem cells, which are derived from embryos, or adult stem cells, which are undifferentiated cells found within specialized tissue. ${ }^{11,12}$ In addition, stem cells are further classified by potency, or the extent of their ability to differentiate into specialized cell types (ie, totipotent, pluripotent, multipotent). ${ }^{11}$ In general, compared with embryonic stem cells, adult stem cells are more limited in their ability to differentiate and typically yield only cells specific to their tissue of origin. ${ }^{11,12}$

This review focuses on 3 specific adult stem cells: (1) cardiosphere-derived cells (CDCs), which are extracted directly from cardiac tissue; (2) mesenchymal stromal cells (MSCs), which reside in a variety of tissues but are most commonly extracted from bone marrow (these cells generate bone, cartilage, and fat cells and have important immunomodulatory functions); and (3) endothelial progenitor cells (EPCs), which are primitive bone marrow cells often found circulating in the blood (these cells assist with repair of endothelium and formation of new blood vessels). ${ }^{12}$

\section{Cardiosphere-Derived Cells}

The heart was once thought to be incapable of regeneration. However, CDCs have been shown to have cardiac-specific markers and stem cell properties with multilineage potential. ${ }^{13,14}$ CDCs are directly isolated from the human heart by percutaneous endomyocardial biopsy, per a procedure established by the first studies to successfully do so (Figure 1). ${ }^{15,16}$

While the exact role of CDCs is not entirely understood, studies that have successfully isolated CDCs have suggested that they are cardiac cell derivatives with angiogenic, anti-inflammatory, and antifibrotic properties-qualities that 


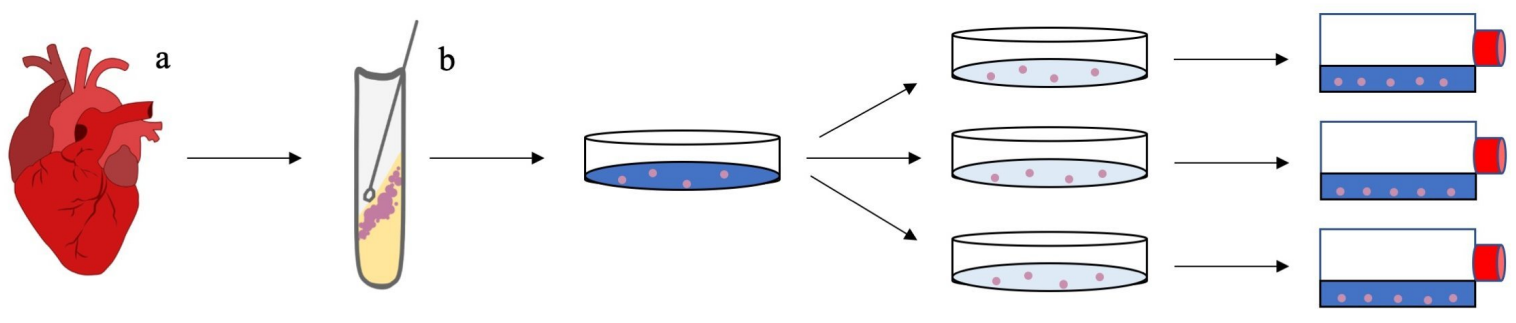

Figure 1. An overview of the procedure used to isolate cardiosphere-derived cells (CDCs).

Myocardial tissue is obtained via atrial or ventricular biopsy. The tissue is then cut into $1-2 \mathrm{~mm}^{3}$ pieces, washed, and partially digested (using trypsin and collagenase). Cells collected during Step II are discarded, while the remaining tissue fragments are cultured as "explants" in Step III; after one to three weeks, a layer of fibroblast-like cells is generated from the adherent "explants." Cells found migrating on top of the cell layer formed in Step III ("phase-bright cells") are collected and seeded on dishes coated with poly-D-lysine; medium is also added to promote growth of the cardiospheres. Following a period of six to ten days, the cardiospheres that have detached from the coated dishes (spherical multicellular clusters) are plated in flasks and grown as monolayers; any adherent cells are discarded. ${ }^{\text {c,d }}$

References

a. https://publicdomainvectors.org/en/free-clipart/Realistic-red-heart/72113.html

b. https://freesvg.org/bacterial-culture-tube

c. Messina E, De Angelis L, Frati G, et al. Isolation and expansion of adult cardiac stem cells from human and murine heart. Circ Res. 2004;95(9):911-921

d. Smith RR, Barile L, Cho HC, et al. Regenerative potential of cardiosphere-derived cells expanded from percutaneous endomyocardial biopsy specimens. Circulation. 2007;115(7):896-908. doi:10.1161/CIRCULATIONAHA.106.655209

are particularly important given the currently accepted paradigm for the pathophysiology of $\mathrm{HFpEF} .{ }^{16} \mathrm{CDC}$ s are also suggested to provide greater improvement in cardiac function when directly compared with bone marrow and adipose-derived stem cells. ${ }^{17}$ Since they were first isolated, autologous CDCs have been used in the treatment of myocardial infarction (MI). ${ }^{18}$ While percutaneous coronary intervention is suggested to have limited efficacy after the 90-minute door-to-balloon time, CDCs administered within the first 4 weeks following an ischemic event were shown to reduce the amount of fibrotic scar tissue by up to $42 \%$ in the first 12 months after MI. ${ }^{18-20}$ Moreover, CDCs have also been suggested to have benefits in nonischemic dilated cardiomyopathy. ${ }^{21}$

While the use of CDCs in HFpEF has not been as extensively studied, 1 animal model has suggested that CDCs might constitute the first effective treatment for HFpEF. ${ }^{22}$ Gallet et $\mathrm{al}^{22}$ conducted a placebo-controlled animal trial in which 1 group of Dalh salt-sensitive rats were fed a high-salt diet for 7 weeks, after which they developed hypertension, cardiac tissue hypertrophy, and HFpEF with increased fibrosis and inflammation. ${ }^{22}$ The rats on the high salt diet then received either placebo or CDCs through intracoronary infusion. ${ }^{22}$ This study found that the group that received CDCs had an increase in survival and a 55\% improvement in left ventricular end-diastolic filling while maintaining an LVEF greater than $70 \%{ }^{22}$ To explain the increase 
in left ventricular end-diastolic filling, the group reported decreases in transcript levels of MMP-2, MMP-7, and MMP-9; collagen I and collagen III; and tissue inhibitor of metalloprotease- 1 in the rats that received CDCs. ${ }^{22}$ This further suggests that CDCs are able to normalize the turnover of extracellular matrix proteins in the setting of HFpEF. ${ }^{22}$ In addition to the antifibrotic effects, the same study found that inflammation was attenuated in the rats treated with CDCs, with a reduction in serum proinflammatory and profibrotic cytokines, and a 2-fold reduction in CD68+ macrophages and CD 45+ leukocytes. ${ }^{22-24}$ Moreover, they found that more than 300 genes that were upregulated or downregulated due to HFpEF had their expression levels rescued after treatment with CDCs. ${ }^{22}$

The study by Gallet et $\mathrm{al}^{22}$ suggested that CDCs directly work to reduce any fibrotic scarring that is already established, while also preventing the formation of new fibrosis. The researchers posited that CDCs work by secreting exosomes that mold the target transcriptome to become more antifibrotic and antiinflammatory. Interestingly, there was no decrease in cardiac hypertrophy or blood pressure associated with their use, suggesting that the improvement in diastolic function was the result of a decrease in inflammation and fibrosis. ${ }^{22}$

Furthermore, the study by Gallet et $\mathrm{al}^{22}$ illuminated the potential of CDCs to inhibit and reverse the progression of HFpEF. Clinical trials are still needed, but previous trials have already evaluated the safety of using CDCs for nonHFpEF conditions by both catheter-based intracoronary infusions and intrapericardial injections. While both modes of delivery have been shown to be safe, it has been suggested that intrapericardial injection yields more favorable outcomes. ${ }^{25-27}$ However, intrapericardial injections require open heart surgery and are much more expensive. While additional studies are needed to evaluate the effectiveness of each administration route in $\mathrm{HFpEF}$, we suspect that direct intrapericardial delivery to a stiff left ventricle in HFpEF will yield a similar degree of safety and benefit as reported by studies that directly injected CDCs into ischemic cardiac tissue. This claim is based on the fact that CDCs injected intrapericardially have yielded the best results in non-HFpEF conditions. ${ }^{25,27}$ In addition, infused magnetically labeled CDCs have been previously reported to localize to ischemic tissue, and future advancements could potentially allow CDCs to localize to ventricular tissue in patients with $\mathrm{HFpEF}$, potentially yielding outcomes similar to intrapericardial injections. ${ }^{28}$ Future studies should also evaluate the effectiveness of cadaver and neonatal CDCs, both of which have been suggested to have positive outcomes in nonHFpEF heart conditions.[@21087; 29

We recognize there is still skepticism about the potential effectiveness of CDCs in patients with HFpEF given that most studies investigating this therapy have been conducted in the setting of local ischemia. To our knowledge, there is no published clinical evidence on the effects of CDCs in treating conditions characterized by large portions of diseased cardiac tissue such as HFpEF, in 
which the entire left ventricle is hypertrophied, inflamed, and fibrotic. However, there is an ongoing phase 2 clinical trial (Regress-HFpEF) studying the use of catheter-based intracoronary infusions in patients with HFpEF (Table 1). If the preliminary evidence from this phase 2 trial is promising, it might lay the foundation for future interventional studies on the use of CDCs in patients with HFpEF. While we are hopeful that CDCs will provide clinically beneficial outcomes, until further clinical studies are conducted, it remains unclear to what degree CDCs will benefit cardiovascular diseases that are not characterized by cardiomyocyte loss. Further studies are also necessary to understand the potential adverse effects of CDCs; with the current level of knowledge, there is concern for tumor formation and ventricular arrhythmias. ${ }^{27}$

\section{Mesenchymal Stromal Cells}

MSCs are an attractive potential heart failure therapy given their ability to moderate immunogenicity and fibrosis, as well as to promote vascular stability in cardiac and other tissues. ${ }^{1}$ These benefits might be particularly effective in the treatment of HFpEF because comorbidities and inflammation are thought to play a primary role in cardiac remodeling and disease pathogenesis.

MSCs are acquired from bone marrow, adipose tissue, and umbilical blood. ${ }^{30}$ Despite the fact that MSCs express major histocompatibility complex class I molecules, they do not elicit a cell-mediated allogeneic immune response. ${ }^{30}$ This relative immune inertness is augmented by active immunosuppression, including IL-10-mediated stimulation of regulatory $\mathrm{T}$ lymphocytes, as well as inhibition of tumor necrosis factor- $\alpha$ and interferon- $\gamma$ production. ${ }^{31}$ In addition, MSCs have been shown to express high levels of tumor necrosis factor-inducible gene 6 (TSG-6), which functions to inhibit neutrophil migration as well as MMP production and activity. ${ }^{32}$ These immunomodulatory properties are pronounced to such a degree that MSCs have been used to significantly improve outcomes of immune-driven disorders, such as graft-versus-host disease. ${ }^{32}$ Other diseases, such as MI, have also benefitted from a type of placental-derived MSC. ${ }^{1}$ Therefore, it is thought that immune modulation via MSCs could improve the underlying inflammation linked to HFpEF progression. ${ }^{1}$

MSCs are also cardioprotective candidates for HFpEF due to their tissue regeneration properties. MSCs are capable of migrating to inflamed tissue and secreting cytokines and growth factors that reduce apoptosis and decrease tissue injury. ${ }^{30}$ In addition to parenchymal protection and regeneration, MSCs show promise for HFpEF therapy because of their vascular anabolic properties. These include promotion of angiogenesis, stimulation of vasculogenesis, and protection of vascular endothelium. 1,30 As such, they have already been used in trials aimed at treating heart conditions, including ischemic cardiomyopathy, and certain forms of peripheral arterial disease. ${ }^{30}$ Given that vascular rarefaction is likely a factor in the pathogenesis of HFpEF, it would also be 
Table 1. Current studies investigating stem cells and biomarkers for the treatment of HFpEF

\begin{tabular}{|c|c|c|c|c|}
\hline $\begin{array}{l}\text { Study Title and } \\
\text { Location }\end{array}$ & Description & Status & Inclusion Criteria & $\begin{array}{c}\text { Study Design } \\
\text { and Type }\end{array}$ \\
\hline $\begin{array}{l}\text { Regression of } \\
\text { Fibrosis \& } \\
\text { Reversal of } \\
\text { Diastolic } \\
\text { Dysfunction in } \\
\text { HFpEF Patients } \\
\text { Treated with } \\
\text { Allogeneic } \\
\text { CDCs (Regress- } \\
\text { HFpEF) } \\
\text { Medical } \\
\text { University of } \\
\text { South Carolina } \\
\text { Charleston, } \\
\text { South Carolina } \\
\text { United States }\end{array}$ & $\begin{array}{l}\text { A double-blinded, placebo-controlled clinical } \\
\text { trial that is evaluating the impact of } \\
\text { intracoronary allogeneic CDCs on a patient's } \\
\text { functional status, exercise tolerance, } \\
\text { exercise hemodynamics, myocardial } \\
\text { interstitial fibrosis, and diastolic function. }\end{array}$ & $\begin{array}{l}\text { Currently } \\
\text { Recruiting } \\
\text { Start Date: } \\
\text { July 12, } \\
2017 \\
\\
\text { Estimated } \\
\text { Completion } \\
\text { Date: } \\
\text { December } \\
2019\end{array}$ & $\begin{array}{l}\text { 1) } \geq 50 \text { years old, } \\
\text { with an LVEF } \\
\geq 50 \% \\
\text { 2) Symptoms and } \\
\text { physical findings } \\
\text { of chronic heart } \\
\text { failure (NYHA } \\
\text { class II - } \\
\text { ambulatory IV) } \\
\text { 3) Treatment with } \\
\text { maximally- } \\
\text { tolerated dose of } \\
\text { diuretic(s) for at } \\
\text { least } 30 \text { days } \\
\text { prior to } \\
\text { randomization } \\
\text { 3) Left atrial (LA) } \\
\text { enlargement } \\
\text { defined by at } \\
\text { least one of the } \\
\text { following: } \\
\text { - LA width } \\
\text { (diameter) } \geq 3.8 \\
\text { cm } \\
\text { - LA length } \geq 5.0 \mathrm{~cm} \\
\text { - LA area } \geq 20 \mathrm{~cm}{ }^{2} \\
\text { - LA volume } \geq 55 \mathrm{~mL} \\
\text { - LA volume index } \\
\geq 29 \mathrm{~mL} / \mathrm{m}^{2} \\
\text { 4) BNP }>125 \mathrm{pg} / \\
\text { mL for patients in } \\
\text { normal sinus } \\
\text { rhythm or }>150 \\
\text { pg/mL for } \\
\text { patients in atrial } \\
\text { fibrillation or } \\
\text { pulmonary } \\
\text { capillary wedge } \\
\text { pressure (PCWP) } \\
>15 \mathrm{mmHg} \text { or } \\
\text { exercise } \mathrm{PCWP} \\
>18 \text { mmHg } \\
\end{array}$ & $\begin{array}{l}\text { Stage II } \\
\text { Clinical Trial } \\
\text { Estimated } \\
\text { Enrollment: } \\
40 \\
\text { participants }\end{array}$ \\
\hline $\begin{array}{l}\text { NT-proBNP in } \\
\text { the } \\
\text { Management of } \\
\text { Discharged } \\
\text { Patients With } \\
\text { Acutely } \\
\text { Decompensated } \\
\text { Heart Failure } \\
\text { and Preserved } \\
\text { Ejection } \\
\text { Fraction } \\
\text { Hospital } \\
\text { Universitario } \\
\text { Virgen de la } \\
\text { Arrixaca } \\
\text { Murcia, Spain }\end{array}$ & $\begin{array}{l}\text { A randomized clinical trial assessing if the } \\
\text { clinical management strategy of monitoring } \\
\text { of NT-proBNP concentrations after hospital } \\
\text { discharge in patients with HFpEF reduces } \\
\text { decompensation and rehospitalizations (due } \\
\text { to heart failure) } 6 \text { months after discharge. }\end{array}$ & $\begin{array}{l}\text { Recruitment } \\
\text { Completed } \\
\text { Start Date: } \\
\text { June } 2015 \\
\text { Completion } \\
\text { Date: } \\
\text { August } \\
2019\end{array}$ & $\begin{array}{l}\text { 1) } \geq 18 \text { years old, } \\
\text { discharged after } \\
\text { hospitalization } \\
\text { for acute heart } \\
\text { failure defined by: } \\
\text { - Dyspnea at rest or } \\
\text { with minimal } \\
\text { effort } \\
\text { - Pulmonary } \\
\text { congestion on } \\
\text { chest X-ray } \\
\text { - NT-pro-BNP } \\
\text { levels in the first } \\
24 \text { hours after } \\
\text { admission: }<50 \\
\text { years: }>450 \mathrm{pg} / \\
\text { mL; } 50-75 \text { years: } \\
>900 \mathrm{pg} / \mathrm{mL} ;>75 \\
\text { years: }>1800 \mathrm{pg} / \\
\text { mL } \\
\text { 2) Administration } \\
\text { of at least } 40 \mathrm{mg} \\
\text { IV furosemide (or }\end{array}$ & $\begin{array}{l}\text { Randomized } \\
\text { Intervention } \\
\text { with Parallel } \\
\text { Assignment } \\
\text { Actual } \\
\text { Enrollment: } \\
167 \\
\text { participants }\end{array}$ \\
\hline
\end{tabular}




\begin{tabular}{|c|c|c|c|c|}
\hline & & & $\begin{array}{l}\text { equivalent) at } \\
\text { admission } \\
\text { 3) Preserved } \\
\text { ejection fraction } \\
\text { (LVEF }>50 \% \text { ) in } \\
\text { echocardiography } \\
\text { performed at } \\
\text { admission and } \\
\text { evidence of } \\
\text { diastolic } \\
\text { dysfunction } \\
\text { defined by: } \\
\text { - } \text { ' }^{\prime}<8 \mathrm{~cm} / \mathrm{s} \text { septal } \\
\text { or }<10 \mathrm{~cm} / \mathrm{s} \\
\text { lateral (TDI mitral } \\
\text { annulus) } \\
\text { - E/e' ratio }>15 \\
\text { - A mitral- }-\mathrm{A} \mathrm{pulmon} \\
>30 \mathrm{msg} \\
\text { - Left atrial volume } \\
\text { index } \geq 34 \mathrm{~mL} / \mathrm{m}^{2} \\
\text { left ventricular } \\
\text { mass index }>95 \mathrm{~g} / \\
\mathrm{m}^{2}(\text { female) or } \\
>115 \mathrm{~g} / \mathrm{m}^{2}(\mathrm{male})\end{array}$ & \\
\hline $\begin{array}{l}\text { Biorepository } \\
\text { Studying the } \\
\text { Relationship } \\
\text { Between } \\
\text { Biomarkers and } \\
\text { Heart Failure } \\
\text { (PREFER-HF) }^{c} \\
\text { Massachusetts } \\
\text { General } \\
\text { Hospital } \\
\text { Boston, } \\
\text { Massachusetts } \\
\text { United States }\end{array}$ & $\begin{array}{l}\text { A prospective study evaluating the } \\
\text { relationship between serial measurement of } \\
\text { biomarkers and echocardiographic features } \\
\text { of diastolic dysfunction in patients with } \\
\text { HFpEF, HFrEF, and patients without a history } \\
\text { of heart failure. Biomarkers studied include } \\
\text { insulin-like growth factor binding protein } 7 \\
\text { (IGFBP7), bone morphogenic protein } 1 \\
\text { (BMP1), and carboxyterminal propeptide of } \\
\text { type-I procollagen (PICP). }\end{array}$ & $\begin{array}{l}\text { Currently } \\
\text { Recruiting } \\
\text { Start Date: } \\
\text { April 7, } \\
2016 \\
\\
\text { Estimated } \\
\text { Completion } \\
\text { Date: } \\
\text { October 7, } \\
2021\end{array}$ & $\begin{array}{l}\text { HFpEF inclusion } \\
\text { criteria LVEF } \\
>50 \% \text {, history of } \\
\text { clinical symptoms } \\
\text { consistent with } \\
\text { HF, and at least } \\
\text { one of the } \\
\text { following } \\
\text { supporting } \\
\text { evidence of HF: } \\
\text { - } \quad \text { NT-proBNP }>125 \\
\text { pg/mL } \\
\text { - BNP }>35 \text { pg/mL } \\
\text { - Capillary wedge } \\
\text { pressure }>15 \\
\text { mmHg on right } \\
\text { heart } \\
\text { catheterization } \\
\text { - LVEDP } \geq 15 \text { mmHg } \\
\text { - Radiographic } \\
\text { evidence of } \\
\text { pulmonary edema } \\
\text { - Improvement in } \\
\text { symptoms with } \\
\text { diuretic initiation } \\
\text { or increase } \\
\text { - CPET evidence of } \\
\text { cardiac etiology of } \\
\text { symptoms } \\
\text { HFrEF inclusion } \\
\text { criteria LVEF } \\
<50 \% \text { history of } \\
\text { clinical symptoms } \\
\text { consistent with } \\
\text { HF and one of the } \\
\text { following } \\
\text { supporting } \\
\text { evidence of HF: } \\
\text { - NT-proBNP }>125 \\
\text { pg/mL } \\
\text { BNP }>35 \text { pg/mL }\end{array}$ & $\begin{array}{l}\text { Prospective } \\
\text { Case-Control, } \\
\text { Observational } \\
\text { Estimated } \\
\text { Enrollment: } \\
3000 \\
\text { participants }\end{array}$ \\
\hline
\end{tabular}




\begin{tabular}{|c|c|c|c|c|}
\hline & & & $\begin{array}{l}\text { - Capillary wedge } \\
\text { pressure >15 } \\
\text { mmHg on right } \\
\text { heart } \\
\text { catheterization } \\
\text { - } \quad \text { LVEDP } \geq 15 \mathrm{mmHg} \\
\text { - } \text { Radiographic } \\
\text { evidence of } \\
\text { pulmonary edema } \\
\text { - Improvement in } \\
\text { symptoms with } \\
\text { diuretic initiation } \\
\text { or increase } \\
\text { CPET evidence of } \\
\text { cardiac etiology } \\
\text { of symptoms }\end{array}$ & \\
\hline $\begin{array}{l}\text { Cell Therapy in } \\
\text { HFpEF } \\
\text { (CELLpEF) }^{\text {d }} \\
\text { University } \\
\text { Medical Center } \\
\text { Ljubljana } \\
\text { Ljubljana, } \\
\text { Slovenia }\end{array}$ & $\begin{array}{l}\text { A randomized clinical trial assessing the } \\
\text { safety and efficacy of transendocardial } \\
\text { CD34+ cell therapy in HFpEF. Outcomes of } \\
\text { interest include myocardial function, } \\
\text { perfusion and electrical activity. }\end{array}$ & $\begin{array}{l}\text { Currently } \\
\text { Recruiting } \\
\text { Start Date: } \\
\text { January } \\
2016 \\
\\
\text { Estimated } \\
\text { Completion } \\
\text { Date: March } \\
2020\end{array}$ & $\begin{array}{l}\text { 1) Preserved left } \\
\text { ventricular } \\
\text { systolic function } \\
\text { on } \\
\text { echocardiography } \\
\text { (LVEF }>50 \% \text { ) } \\
\text { 2) Evidence of } \\
\text { diastolic } \\
\text { dysfunction on } \\
\text { echocardiography } \\
\text { (E/e'>15) } \\
\text { 3) Symptoms of } \\
\text { heart failure } \\
\text { (NYHA functional } \\
\text { class II or III) } \\
\text { 4) NT-proBNP } \\
\text { levels }>300 \text { pg/ } \\
\text { mL }\end{array}$ & $\begin{array}{l}\text { Randomized } \\
\text { Intervention } \\
\text { with Parallel } \\
\text { Assignment } \\
\text { Estimated } \\
\text { Enrollment: } \\
30 \\
\text { participants }\end{array}$ \\
\hline
\end{tabular}

\section{References}

a. https://clinicaltrials.gov/ct2/show/NCT02941705?term=Michael+Zile\&rank=1

b. https://clinicaltrials.gov/ct2/show/record/NCT02807168? cond=Heart+Failure+with+PrePreser+Ejection+Fraction\&draw=4

c. https://clinicaltrials.gov/ct2/show/study/NCT03480633? cond=Heart+Failure+with+PresPrese+Ejection+Fraction\&draw=3

d. https://clinicaltrials.gov/ct2/show/NCT02923609

worthwhile to investigate applications of MSCs derived from adipose tissue, which have been shown to promote more vessel formation and branching when compared with MSCs derived from bone marrow. ${ }^{30}$

Although MSCs show promise in cardiac-specific regeneration and localized immune homeostasis, recent interest has centered around the potential for systemic treatment of HFpEF. When placental-derived MSCs are intravenously co-administered with cardiac-derived adherent proliferating cells, a form of stem cell with MSC-like properties extracted from the heart endocardium, there is evidence of systemic immune control. ${ }^{1,33}$ Thus, venous forms of delivery may be superior to other modes given the systemic inflammation associated with HFpEF. ${ }^{1}$ In cases without total-body immune involvement, MSCs may nonetheless be effective in improving inflammation limited to the heart. This is particularly true in light of the ability of MSCs to localize to areas of inflammation. ${ }^{30}$ Given that CDCs have already demonstrated a capacity in vivo (with Dalh salt-sensitive rats) to improve 
cardiac function in HFpEF, potential adjunct use of MSCs should be principally based on their ability to minimize the chronic systemic inflammation associated with HFpEF. ${ }^{22,33}$ However, the use of MSCs is not without potential adverse effects, such as thrombosis and immune rejection. ${ }^{34}$ Additionally, given the immunomodulatory function of MSCs, excessive suppression of lymphocytes and cytokine production-especially later in the disease course-could lead to infection or malignancy. ${ }^{34}$

\section{Endothelial Progenitor Cells}

As a result of the complexity and heterogeneity of diagnosing HFpEF, some researchers have sought to identify biomarkers as a way to better understand the pathogenesis and improve the diagnosis, management, and prognosis of HFpEF. There are 2 ongoing studies investigating the clinical applicability of specific biomarkers in the diagnosis and management of HFpEF (Table 1). One of the most well-established biomarkers used to assess the severity of heart failure is N-terminal pro-B-type natriuretic peptide (NT-proBNP), which is released by cardiomyocytes under conditions of myocardial stretch. ${ }^{2}$ However, because NT-proBNP is elevated in many diseases, it is generally considered to be an insufficiently sensitive biomarker for HFpEF when used in isolation. ${ }^{2}$ To this end, EPCs have emerged as a more specific biomarker candidate and as a potential treatment option for HFpEF. ${ }^{35}$ Moreover, researchers believe that EPCs may be useful in differentiating between HFpEF and HFrEF, and could provide insight into the future risk of heart failure development in asymptomatic patients. ${ }^{35}$

EPCs are precursor endothelial cells that originate in bone marrow and are released into the circulation in response to endothelial damage. ${ }^{36}$ Given their clonogenic potential and their ability to be mobilized into the circulation to produce mature endothelial cells, EPCs support angiogenesis, vasculogenesis, and repair of damaged and ischemic endothelium. ${ }^{37,38}$ In addition, circulating EPCs are associated with inflammation, oxidative stress, neurohormonal disarray, and myocardial remodeling, all of which are now understood to be critical to HFpEF pathophysiology. ${ }^{2}$ With respect to the severity of HFpEF, EPCs display a biphasic pattern: levels are elevated in stable disease, but rapidly decline with progression to advanced heart failure. While this pattern is not fully understood, it has been proposed that the chronically elevated angiotensin II levels of long-standing hypertension, a comorbidity highly associated with HFpEF, impairs EPC migratory capability, reduces EPC telomerase activity, and accelerates EPC deterioration-this helps to explain the rapid decline in EPCs observed with advanced disease. ${ }^{39}$

Two groups of EPCs are relevant to the discussion of HFpEF: early EPCs and late EPCs. The early EPCs, so called because they produce endothelial-like cells within a few days of culture in vivo, are of monocytic origin and release microparticles such as cytokines, chemokines, and growth factors contributing to angiogenesis. ${ }^{39}$ Early EPCs modulate the activity of tissue resident cells, 
mobilize other cell types, and are easily assessed in blood samples via flow cytometry. ${ }^{39}$ Late EPCs, by contrast, are found in small quantities in the circulation and typically reside in the endothelium. The pattern of early EPCs, along with the circulating microparticles they produce, has been used to study the difference between $\mathrm{HFpEF}$ and $\mathrm{HFrEF} .{ }^{39}$ More specifically, these endothelial cell-derived microparticles (EMPs) are believed to be an important aspect of intercellular communication that may be able to indicate inflammation, oxidative stress, neurohormonal disarray, and myocardial and matrix remodeling. ${ }^{2,39}$ In fact, EMPs are also thought to play an important role in regulatory pathways because they use cell surface receptors to target certain cell types and have been found to be abnormal in both patients with hypertension and patients with HFrEF. ${ }^{39}$

Research into the complex interplay between EPCs, EMPs, and the pathogenesis of HFpEF is scarce. However, a recent study found that EMPs can induce proangiogenic capacities in EPCs, specifically human $\mathrm{CD}_{4} 4^{+}$ primitive progenitor cells and $\mathrm{CD} 14^{+}$monocytic progenitor cells, and that they are also instrumental in guiding mature endothelial cells to express a procoagulative, proinflammatory, and provasoconstrictive phenotype. ${ }^{35}$ However, evidence also suggests that EMPs, when freely circulating and not targeting specific cells, are apoptotic; thus, the balance between angiogenic EPCs and apoptotic EMPs is critical for cardiac regeneration and endothelial function. ${ }^{35}$ Additionally, new research suggests that the ratio of circulating EPCs to EMPs can serve as a biomarker used to relate activation and/or apoptosis of endothelial cells to endothelial dysfunction; these events are important in the development and progression of heart failure. ${ }^{40}$

To better delineate the development of phenotypes that ultimately lead to heart failure, as well as to better understand how EMPs can induce proangiogenic capacities in $\mathrm{CD} 14^{+}$cells in $\mathrm{HFpEF}$, angiogenic EPCs labeled as $\mathrm{CD} 14^{+} \mathrm{CD} 309^{+}$were investigated. ${ }^{35}$ The study sought to identify potential differential biomarker patterns that could prove useful in better defining HFpEF. ${ }^{35}$ Prior to this study, NT-proBNP, soluble ST2, galectin-3, and highsensitivity cardiac-specific troponins were studied in detail but were not found to be of much diagnostic benefit in HFpEF. ${ }^{35}$ In this study, Berezin et al ${ }^{35}$ labeled apoptotic EMPs with CD $31^{+} /$annexin $\mathrm{V}^{+}$markers and found that, in combination with NT-proBNP and clinical data, the ratio of $\mathrm{CD} 31^{+} /$annexin $\mathrm{V}^{+}$EMPs to CD14 ${ }^{+} \mathrm{CD} 309^{+}$EPCs served as a useful biomarker for HFpEF and could be beneficial in differentiating HFpEF from HFrEF. ${ }^{35}$ More specifically, this study found that patients with HFpEF have lower ratios of CD31 1 annexin $\mathrm{V}^{+}$EMPs to CD14 ${ }^{+} \mathrm{CD} 309+\mathrm{EPC}$ s when compared with patients with HFrEF. 35

The results of this study demonstrated that the balance between elevated levels of EPCs, which are angiogenic, and apoptotic EMPs can be used to create directed therapies to control or reverse HFpEF pathogenesis, as well as to 
develop a method for risk-stratification in patients with HFpEF. ${ }^{35}$ For example, if the lower ratios of $\mathrm{CD} 31^{+} /$annexin $\mathrm{V}^{+}$EMPs to $\mathrm{CD} 14^{+} \mathrm{CD} 309^{+}$ EPCs in patients with HFpEF described here are the result of decreased EMPs and increased EPCs, this might indicate an environment conducive to endothelial repair. ${ }^{35}$ If, however, this ratio begins to increase with decompensating $\mathrm{HFpEF}$ - as a result of decreasing EPC levels_it may favor a more apoptotic environment, indicating an appropriate time to administer EPCs to slow the progression of HFpEF. This has potential to improve cardiac outcomes in patients and could constitute a future stem cell therapy for HFpEF. There is an ongoing phase 2 clinical trial (CELLpEF) assessing the safety and efficacy of transendocardial CD34+ cell therapy in patients with HFpEF (Table 1). This study follows a pilot trial, conducted by the same group, that administered transendocardial CD34+ injections to areas of diastolic dysfunction in 14 patients with $\mathrm{HFpEF}{ }^{41}$ In addition to being feasible and safe, the pilot study found that the intervention improved diastolic dysfunction (in terms of left ventricular filling pressures and local systolic strain) and decreased NT-proBNP levels. ${ }^{41}$

Additional research, however, is needed to further analyze the complex relationship between EPC and EMP levels, and its impact on cardiac remodeling. For example, it is still unknown whether the fluctuations in EPC and EMP levels are part of the pathogenesis of HFpEF or part of the body's attempt to respond to pathogenic stress. ${ }^{39}$ Furthermore, it is essential to distinguish between the various circulating EPCs (those of monocytic and nonmonocytic origin, for example) and the various EMPs (those which are shed from endothelial cells vs those shed from platelets) as they could potentially correspond to different phenotypes of HFpEF. ${ }^{39}$

Given the many poorly understood aspects of endothelial dysfunction, further research is needed to determine the exact mechanisms behind the differences in the ratios of EMPs to EPCs in HFrEF and HFpEF. It needs to be determined whether the ratios are lower in HFpEF, relative to HFrEF, because apoptotic EMPs are elevated in HFrEF (due to ischemia) or because there is an inherent alteration in vascular hemodynamics associated with HFpEF. ${ }^{39}$ Once these questions are fully answered, new treatment modalities may be developed and could potentially work to decrease morbidity and mortality in patients with HFpEF.

\section{Conclusion}

HFpEF accounts for half of the global heart failure burden and yet there are currently no effective treatment options. Nevertheless, there is optimism following recent advances by researchers in understanding the pathophysiology of HFpEF. Basic science research over the past 20 years suggests that HFpEF is much more complicated than simply diastolic dysfunction. Studies have suggested that HFpEF is characterized by an inflammatory state created by the common presence of multiple comorbidities in patients with HFpEF, who 
tend to be older than patients with HFrEF. This research has led to a more nuanced understanding of the pathophysiology of HFpEF, one that does not rely exclusively on the presence of myocardial fibrosis as was previously done.

This newfound understanding of the pathophysiology of HFpEF, and the failure of pharmacological therapy to treat HFpEF up to this point, has generated interest in stem cells as a potential therapy option. While there has not been extensive research to date on stem cell therapy for HFpEF, there is ongoing research, with studies focusing on CDCs, MSCs, and EPCs. Currently, research on CDCs is the most advanced and appears to be the most promising given a recent rat study, which found that intracoronary-injected CDCs are able to reverse the progression of HFpEF and increase survival. ${ }^{23}$ In addition to the promising data on CDCs, MSCs hold promise of their own given their ability to decrease systemic inflammation. Based on the effects of these cell therapies in vivo, we posit that while CDCs and MSCs may have individual benefits, future work should also evaluate dual therapies by combining intracoronary CDCs and intravenous MSCs.

In terms of ongoing clinical research, there are 2 studies evaluating potential biomarkers for HFpEF, a phase 2 clinical trial studying the potential of CDCs to treat HFpEF and another phase 2 clinical trial investigating transendocardial CD34+ cell therapy in patients with HFpEF (Table 1). As a result, we remain optimistic about the future application of stem cell therapy in the treatment of HFpEF and about furthering understanding of the pathogenesis of HFpEF. We hypothesize that, in the future, stem cells will have the ability to stop the progression of HFpEF and decrease the morbidity and mortality associated with the condition.

While stem cell therapy is more expensive and invasive compared with pharmacological therapy, it is advantageous in that stem cells can potentially halt and reverse the progression of disease. As a result, stem cells appear poised to have a more direct and more permanent effect on the disease mechanisms of HFpEF when compared with pharmacological therapy. As research continues to advance and biomarkers continue to be developed, there will be more potential for beneficial treatment options incorporating stem cell therapy. It is likely that these advancements will improve the quality of life for patients with HFpEF. 


\section{REFERENCES}

1. Tschöpe C, Van Linthout S, Kherad B. Heart failure with preserved ejection fraction and future pharmacological strategies: A glance in the crystal ball. Curr Cardiol Rep. 2017;19(8). doi:10.1007/ $\underline{\text { s11886-017-0874-6 }}$

2. Yancy CW, Jessup M, Bozkurt B, et al. ACCF/AHA guideline for the management of heart failure: A report of the American College of Cardiology Foundation/American Heart Association Task Force on Practice Guidelines.J Am Coll Cardiol. 2013;62(16):e147-239. https://doi.org/ doi:0.1016/j.jacc.2013.05.019.

3. Røe ÅT, Aronsen JM, Skårdal K, et al. Increased passive stiffness promotes diastolic dysfunction despite improved $\mathrm{Ca} 2+$ handling during left ventricular concentric hypertrophy. Cardiovascular Research. 2017;113(10):1161-1172. doi:10.1093/cvr/cvx087

4. Gladden JD, Linke WA, Redfield MM. Heart failure with preserved ejection fraction. Pflugers Arch - Eur J Physiol. 2014;466(6):1037-1053. doi:10.1007/s00424-014-1480-8

5. Owan TE, Hodge DO, Herges RM, Jacobsen SJ, Roger VL, Redfield MM. Trends in prevalence and outcome of heart failure with preserved ejection fraction. N Engl J Med. 2006;355(3):251-259.

6. Alehagen U, Benson L, Edner M, Dahlström U, Lund LH. Association between use of statins and mortality in patients with heart failure and ejection fraction of $\geq 50 \%$. Circ Heart Fail. 2015;8(5):862-870. doi:10.1161/circheartfailure.115.002143

7. Marume K, Takashio S, Nagai T, et al. Effect of Statins on Mortality in Heart Failure With Preserved Ejection Fraction Without Coronary Artery Disease —— Report From the JASPER Study. Circ J. 2019;83(2):357-367. doi:10.1253/circj.cj-18-0639

8. Tsujimoto T, Kajio H. Favorable effects of statins in the treatment of heart failure with preserved ejection fraction in patients without ischemic heart disease. International Journal of Cardiology. 2018;255:111-117. doi:10.1016/j.ijcard.2017.12.109

9. How can stem cells advance medicine? Nat Rep Stem Cells. June 2007. doi:10.1038/ stemcells.2007.23

10. Packer M. The epicardial adipose inflammatory triad: Coronary atherosclerosis, atrial fibrillation, and heart failure with a preserved ejection fraction. Eur J Heart Fail.

2018;20(11):1567-1569. doi:10.1002/ejhf.1294

11. Hima Bindu A, Srilatha B. Potency of various types of stem cells and their transplantation. $J$ Stem Cell Res Ther. 2011;1(3). doi:10.4172/2157-7633.1000115

12. National Institutes of Health. Stem cell basics. https://stemcells.nih.gov/info/basics.htm. Accessed December 1, 2019.

13. Davis DR, Smith RR, Marbán E. Human cardiospheres are a source of stem cells with cardiomyogenic potential. Stem Cells. 2010;28(5):903-904. doi:10.1002/stem.413

14. White AJ, Smith RR, Matsushita S, et al. Intrinsic cardiac origin of human cardiospherederived cells. European Heart Journal. 2013;34(1):68-75. doi:10.1093/eurheartj/ehr172

15. Messina E, De Angelis L, Frati G, et al. Isolation and expansion of adult cardiac stem cells from human and murine heart. Circ Res. 2004;95(9):911-921.

16. Smith RR, Barile L, Cho HC, et al. Regenerative potential of cardiosphere-derived cells expanded from percutaneous endomyocardial biopsy specimens. Circulation. 2007;115(7):896-908. doi:10.1161/circulationaha.106.655209 
17. Li T-S, Cheng K, Malliaras K, et al. Direct comparison of different stem cell types and subpopulations reveals superior paracrine potency and myocardial repair efficacy with cardiospherederived cells. Journal of the American College of Cardiology. 2012;59(10):942-953. doi:10.1016/ j.jacc.2011.11.029

18. Makkar RR, Smith RR, Cheng K, et al. Intracoronary cardiosphere-derived cells for heart regeneration after myocardial infarction (CADUCEUS): A prospective, randomised phase 1 trial. The Lancet. 2012;379(9819):895-904. doi:10.1016/s0140-6736(12)60195-0

19. Moscucci M, Eagle KA. Door-to-balloon time in primary percutaneous coronary intervention: Is the 90-minute gold standard an unreachable chimera? Circulation. 2006;113(8):1048-1050.

20. Sun Y, Chi D, Tan M, et al. Cadaveric cardiosphere-derived cells can maintain regenerative capacity and improve the heart function of cardiomyopathy. Cell Cycle. 2016;15(9):1248-1256. doi:10.1080/15384101.2016.1160973

21. Aminzadeh MA, Tseliou E, Sun B, et al. Therapeutic efficacy of cardiosphere-derived cells in a transgenic mouse model of non-ischaemic dilated cardiomyopathy. European Heart Journal. 2015;36(12):751-762. doi:10.1093/eurheartj/ehu196

22. Gallet R, de Couto G, Simsolo E, et al. Cardiosphere-Derived Cells Reverse Heart Failure With Preserved Ejection Fraction in Rats by Decreasing Fibrosis and Inflammation.JACC: Basic to Translational Science. 2016;1(1-2):14-28. doi:10.1016/j.jacbts.2016.01.003

23. Collier P, Watson CJ, Voon V, et al. Can emerging biomarkers of myocardial remodelling identify asymptomatic hypertensive patients at risk for diastolic dysfunction and diastolic heart failure? European Journal of Heart Failure. 2011;13(10):1087-1095. doi:10.1093/eurjhf/hfr079

24. Zile MR, Baicu CF, S. Ikonomidis J, et al. Myocardial stiffness in patients with heart failure and a preserved ejection fraction: Contributions of collagen and titin. Circulation.

2015;131(14):1247-1259. doi:10.1161/circulationaha.114.013215

25. Blázquez R, Sánchez-Margallo FM, Crisóstomo V, et al. Intrapericardial delivery of cardiosphere-derived cells: An immunological study in a clinically relevant large animal model. Vinci MC, ed. PLoS ONE. 2016;11(2):e0149001. doi:10.1371/journal.pone.0149001

26. Malliaras K, Makkar RR, Smith RR, et al. Intracoronary cardiosphere-derived cells after myocardial infarction: Evidence of therapeutic regeneration in the final 1-year results of the CADUCEUS trial (CArdiosphere-Derived aUtologous stem CElls to reverse ventricUlar dySfunction. Journal of the American College of Cardiology. 2014;63(2):110-122. doi:10.1016/ j.jacc. 2013.08.724

27. Lee S-T, White AJ, Matsushita S, et al. Intramyocardial injection of autologous cardiospheres or cardiosphere-derived cells preserves function and minimizes adverse ventricular remodeling in pigs with heart failure post-myocardial infarction. Journal of the American College of Cardiology. 2011;57(4):455-465. doi:10.1016/j.jacc.2010.07.049

28. Cheng K, Li T-S, Malliaras K, Davis DR, Zhang Y, Marbán E. Magnetic targeting enhances engraftment and functional benefit of iron-labeled cardiosphere-derived cells in myocardial infarction. Circulation Research. 2010;106(10):1570-1581. doi:10.1161/circresaha.109.212589

29. Simpson DL, Mishra R, Sharma S, Goh SK, Deshmukh S, Kaushal S. A strong regenerative ability of cardiac stem cells derived from neonatal hearts. Circulation. 2012;126(11 Suppl 1):S46-53.

30. Sharma RR, Pollock K, Hubel A, McKenna D. Mesenchymal stem or stromal cells: A review of clinical applications and manufacturing practices. Transfusion. 2014;54(5):1418-1437.

doi:10.1111/trf.12421 
31. Rasmusson I, Ringdén O, Sundberg B, Le Blanc K. Mesenchymal stem cells inhibit the formation of cytotoxic $T$ lymphocytes, but not activated cytotoxic $T$ lymphocytes or natural killer cells. Transplantation. 2003;76(8):1208-1213.

32. Ankrum J, Karp JM. Mesenchymal stem cell therapy: Two steps forward, one step back. Trends in Molecular Medicine. 2010;16(5):203-209. doi:10.1016/j.molmed.2010.02.005

33. Haag M, Stolk M, Ringe J, et al. Immune attributes of cardiac-derived adherent proliferating (CAP) cells in cardiac therapy.J Tissue Eng Regen Med. 2013;7(5):362-370. doi:10.1002/term.531

34. Saeedi P, Halabian R, Imani Fooladi AA. A revealing review of mesenchymal stem cells therapy, clinical perspectives and Modification strategies. Stem Cell Investig. 2019;6:34. doi:10.21037/ $\underline{\text { sci.2019.08.11 }}$

35. Berezin AE, Kremzer AA, Martovitskaya YV, Berezina TA, Gromenko EA. Pattern of endothelial progenitor cells and apoptotic endothelial cell-derived microparticles in chronic heart failure patients with preserved and reduced left ventricular ejection fraction. EBioMedicine. 2016;4:86-94. doi:10.1016/j.ebiom.2016.01.018

36. Chiang C-H, Huang P-H, Leu H-B, et al. Decreased circulating endothelial progenitor cell levels in patients with heart failure with preserved ejection fraction. Cardiology. 2013;126(3):191-201. doi:10.1159/000351973

37. Astori G, Soncin S, Lo Cicero V, et al. Bone marrow derived stem cells in regenerative medicine as advanced therapy medicinal products. Am J Transl Res. 2010;2(3):285-295.

38. Szmitko PE, Fedak PW, Weisel RD, Stewart DJ, Kutryk MJ, Verma S. Endothelial progenitor cells: New hope for a broken heart. Circulation. 2003;107(24):3093-3100.

39. Shantsila E, Lip GYH. Endothelial progenitors and blood microparticles: Are they relevant to heart failure with preserved ejection fraction? EBioMedicine. 2016;4:5-6. doi:10.1016/ j.ebiom.2016.01.025

40. Fujisue K, Sugiyama S, Matsuzawa Y, et al. Prognostic significance of peripheral microvascular endothelial dysfunction in heart failure with reduced left ventricular ejection fraction. Circ J. 2015;79(12):2623-2631. doi:10.1253/circj.cj-15-0671

41. Vrtovec B, Frljak S, Jaklic M, et al. Abstract 15952: A pilot trial of CD34+ cell therapy in heart failure with preserved ejection fraction. Circulation. 2017;136:A15952. 